\title{
AN OVERVIEW OF STATIC SYNCHRONOUS SERIES COMPENSATOR
}

\author{
${ }^{1 *}$ Saurabh Pingale $\quad{ }^{2}$ Alviya Mahevash ${ }^{3}$ Nitin Joshi \\ ${ }^{1}$ Executive(Maintenance), Legrand India Ltd., Jalgaon,India \\ ${ }^{2}$ Assistant Professor, Yeshwantrao Chavan College of Engineering, India \\ ${ }^{3}$ Dy. Manager(Maintenance) Legrand India Ltd. Jalgaon,India \\ * Communicating author Email: \{saurabhpingale1@gmail.com\}
}

\begin{abstract}
Static synchronous series compensator (SSSC) is generally used as a voltage source converter based series compensator. SSSC is a chain tool wherein a synchronous voltage injects a essential frequency voltage in series with the transmission line. For strength transmission utility this device is extra attractive because it has non -capacitor conduct and superior working traits. An SSSC injects an almost sinusoidal voltage, of variable importance, in series with transmission line and this injected voltage is sort of in quadrature with the line cutting-edge and consequently emulates an inductive or a capacitive reactance in series with the transmission line and this emulated variable reactance inserted with the aid of the injected voltage supply, impacts the electric energy glide within the transmission line. This paper proposes 4 modes of operation of SSSC tool and their respective power-angle curves are validated. This model is simulated the usage of MATLAB/SIMULINK R-2016.
\end{abstract}

Keywords - SSSC, FACTS, series controller, voltage source converter, power transmission, MATLAB/SIMULINK.

\section{Introduction}

Energy machine there are massive no of disturbances consisting of variant in voltage, brief instability, bad energy issue, sub synchronous resonance etc. so as to triumph over these issues a static series compensating tool may be used. This tool is connected in collection with transmission line to improve the overall performance of the machine [1]. the main goal of the collection compensating device are to hold voltage balance, improvement of transient stability, power oscillation damping, sub synchronous damping and so forth. SSSC is one of the collection compensating gadgets [2-3].

SSSC is one of the maximum critical records Controller output ac voltage is in collection with the line. It's miles based totally on a voltage source converter shown in fig. 1 (a) [4]. Commonly the injected voltage in series would be quite small in comparison to the road voltage, and the insulation to floor might be pretty high. With the precise insulation among the primary and the secondary of the transformer, the converter system is located on the ground capability unless the complete converter system is positioned on a platform duly insulated from floor [5-7]. without a further power supply, SSSC can only inject a variable voltage, which is 90 tiers leading or lagging the contemporary. The primary of the transformer and therefore the secondary in addition to the converter have to deliver full line modern-day consisting of the fault current except the converter is briefly bypassed at some stage in severe line faults.

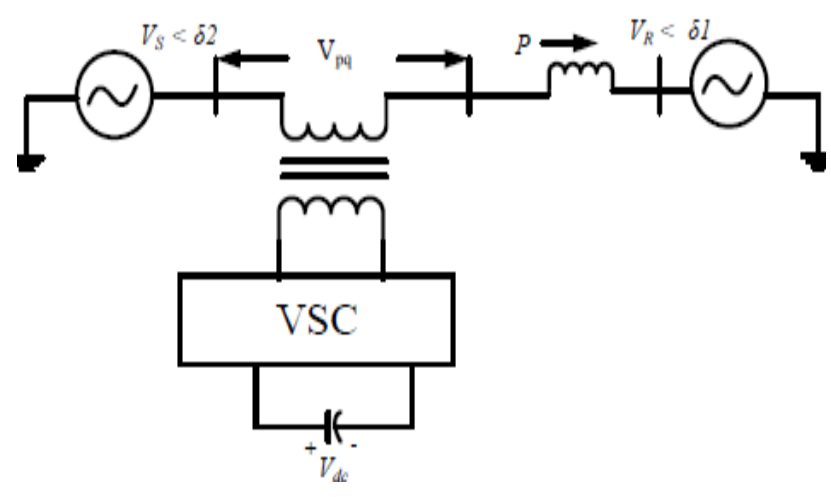

Fig. 1(a): Schematic of SSSC

$$
\begin{aligned}
& P=\frac{V_{S} \times V_{R}}{X} \times \sin (\delta 1-\delta 2) \\
& P=\frac{V_{S} \times V_{R}}{X} \times \sin (\delta 1)(\text { since } \delta 2=0)
\end{aligned}
$$

Where, $P=$ Real power in the system.

$\mathrm{VS}=$ Sending end voltage.

$\mathrm{VR}=$ Receiving end voltage.

$\delta=$ Angle between sending end and receiving end.

$\mathrm{X}=$ Line Impedance.

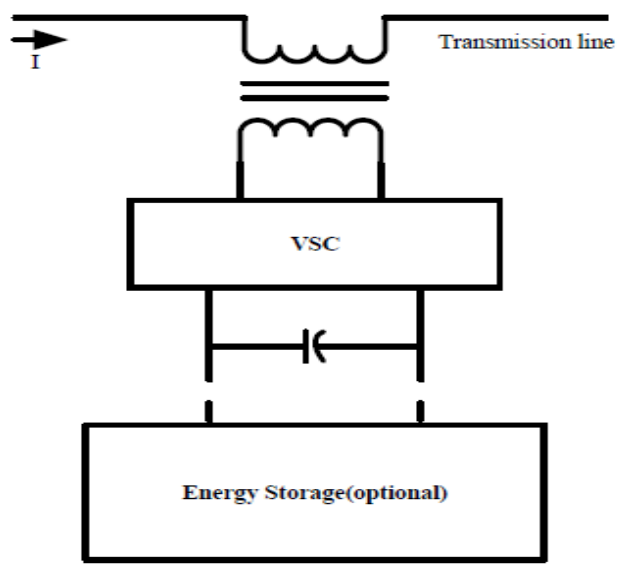

Fig. 1(b): Schematic of VSC based SSSC with energy-storage

Energy-storage or superconducting magnetic storage can also be connected to a series controller as shown in fig.1(b) to inject a voltage vector of variable angle in series with the line. With energy storage, the effectiveness of power oscillation damping increases.

Merits of SSSC can be explained as: 
1) The power carrying capacity of the line can be increased to values up to the thermal limits by imposing the current carrying capacity of the conductors.

2) It contributes to best possible system operation by improving voltage profile and reducing power losses.

3) The problem of voltage fluctuations and dynamic overvoltages can be overcome by using SSSC.

The applications of the SSSC are,

1) To control the power flow,

2) To increase the power transfer limits,

3) To improve the transient stability,

4) To dampen power system oscillations,

5) To dampen Sub-Synchronous Resonance (SSR)

6) Power Swing Damping [8-10].

\section{Operating principle}

A SSSC is a series compensator, which will inject the voltage in the line for maintaining system parameters. As the SSSC is a injecting voltage sources in series with line, we can see that as a controlled voltage source in series with transmission line. For analyzing the effect of SSSC in system we can replace the SSSC with their equivalent synchronous voltage sources (SVS) in system. It can produce a set of (three) alternating, sinusoidal voltage at desired frequency and with controllable and phase angle.

$$
V q=-j X c I=-J k X I
$$

Where the symbols have their general meanings in electrical engineering. Thus, the output voltage of the synchronous voltage source is a function of a line current. For capacitive compensation, the output voltage lags the line current by 90 . The SVS output voltage can be reversed by simple control action to make it lead or lag the line current by 90.

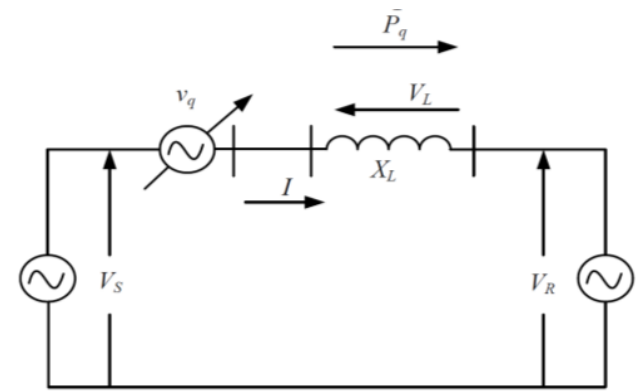

Fig. 2(a.): The elementary two machine system with SSSC

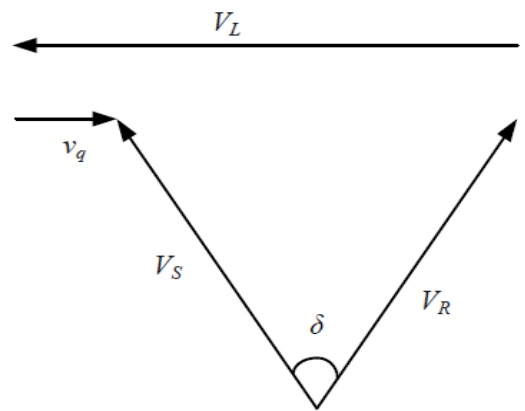

Fig.2(b): Associated phasor diagram

Case 1 : For uncompensated line $\mathrm{V}_{\mathrm{q}}=0$.

Where, voltage injected by SSSC is zero in line. $\mathrm{Vx}=\mathrm{V}_{\text {eff, }}$ shown in fig. 3.

$$
P=\frac{V_{S} \times V_{R}}{X} \times \sin (\delta)
$$
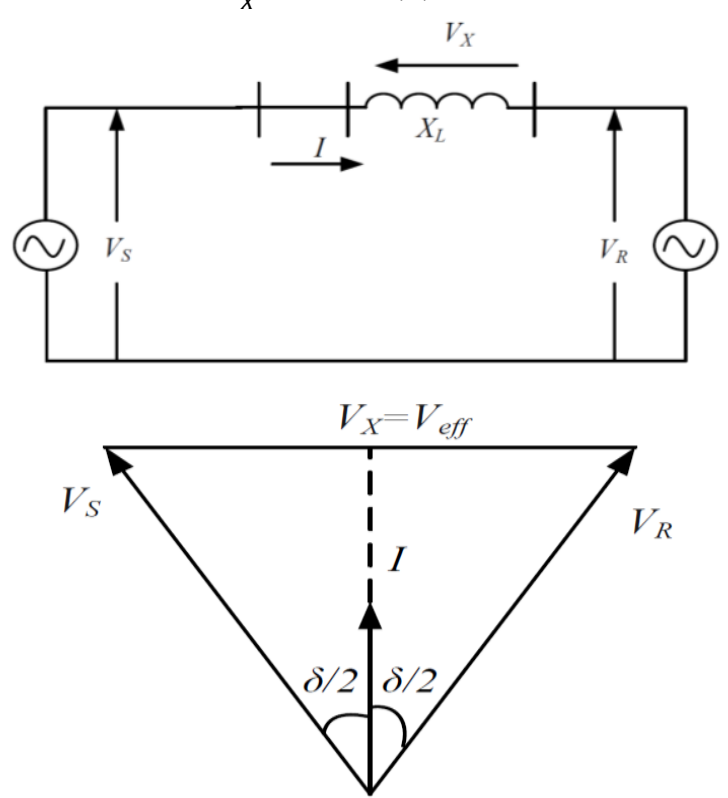

Fig. 3: Uncompensated line $\mathrm{V}_{\mathrm{q}}=0$.

Case 2 : Inductive compensated line.

Where, $\mathrm{I}$ is a current of uncompensated line.

$$
\begin{gathered}
V q=|V q| e^{+j \frac{\Pi}{2} I} \\
V_{S}=V q+V_{S}+V_{R} \\
V_{\text {Seff }}=V_{S}-V_{R}
\end{gathered}
$$

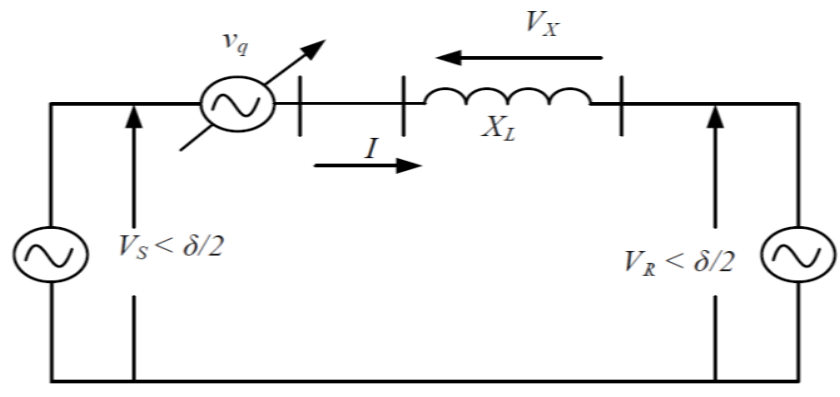

Fig.4(a): Two machine system with inductively compensated line. 


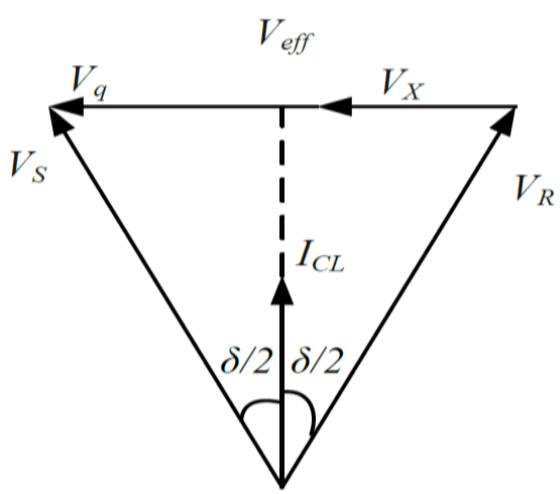

Fig.4(b): Inductively compensated line

Case 3 : Capacitive compensated line.

Fig.5 shows same diagram we have used in inductive compensation line. Some modification we required.

$$
V q=|V q| e^{-j \frac{\Pi}{2} I}
$$$$
V_{S}=-V q+V_{S}+V_{R}
$$$$
V_{\text {Seff }}=V_{q}+V_{S}
$$$$
V_{X}=V_{\text {seff }}+V_{q}
$$
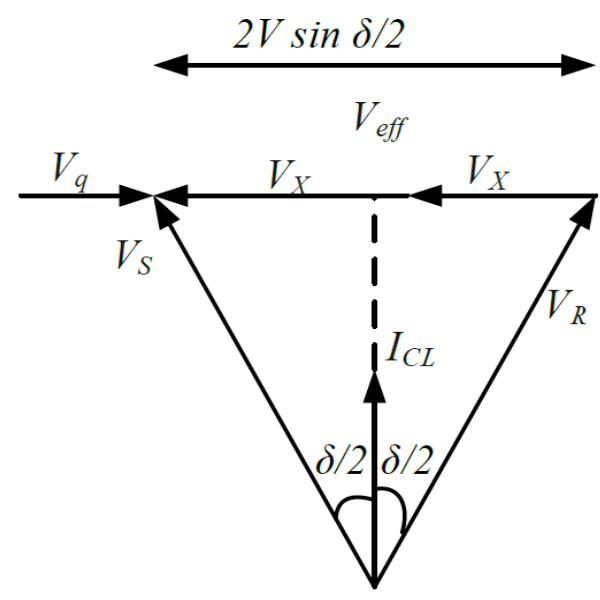

Fig.5: Capacitive compensation phasor diagram.

Where, $\mathrm{V}_{\mathrm{S}}=\mathrm{V}_{\mathrm{R}}=\mathrm{V}$. Calculation for active power of SSSC

$$
\begin{gathered}
2 v \sin \frac{\delta}{2}+V q=V_{X}=I_{C L} X \\
I_{C L} X=\frac{2 V}{X} \sin \frac{\delta}{2}+\frac{V_{2}}{X} \\
P=V \cos \frac{\delta}{2} I_{C L}=V \cos \frac{\delta}{2}\left(\frac{2 V}{X} \sin \frac{\delta}{2}+\frac{V_{q}}{X}\right) \\
=\frac{2 V^{2}}{X} \sin \frac{\delta}{2}+\cos \frac{\delta}{2}+\frac{V V_{q}}{X} \\
P=\frac{V^{2}}{X} \sin \frac{\delta}{2} \pm \cos \frac{\delta}{2} \frac{V V_{q}}{X} \\
P q=\frac{V^{2}}{X_{L}} \sin +\delta \cos \frac{\delta}{2} \frac{V V_{q}}{X_{L}}
\end{gathered}
$$

\section{Operating Modes of SSSC}

The SSSC can be operating into four operational modes.
A. Pure Voltage Regulator
B. Impedance Regulator
C. Quadrature Booster
D. Pure Phase Shifter

\section{A. Pure Voltage Regulator}

Pure voltage regulator mode is used to regulate the pure voltage. This mode is explained by the voltage phasor diagram as shown in fig.6(a). The voltage injected by SSSC in line at $\pm V q<0$. In this mode, the phasor diagram clearly shows that voltage Vpq will be exactly in phase with VS and the resultant is therefore $V_{\text {Seffective }}$. Hence $V_{\text {Seff }}=V_{S}+V p q . \delta$ is the angle between the sending end voltage and the receiving end voltage. Power angle curve is shown in fig. 6(b).

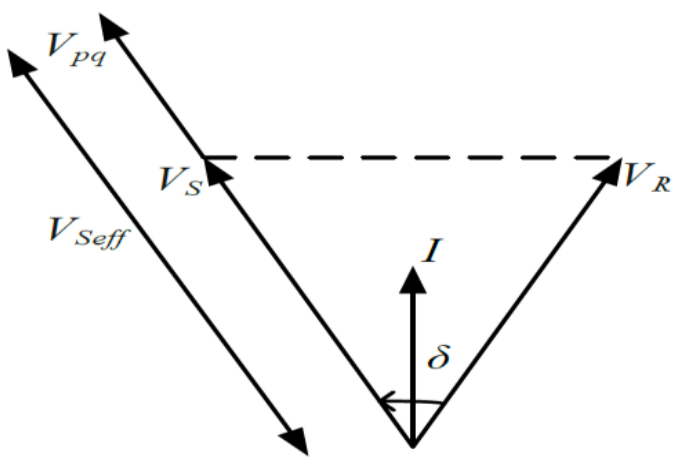

Fig.6(a): Pure voltage regulator mode

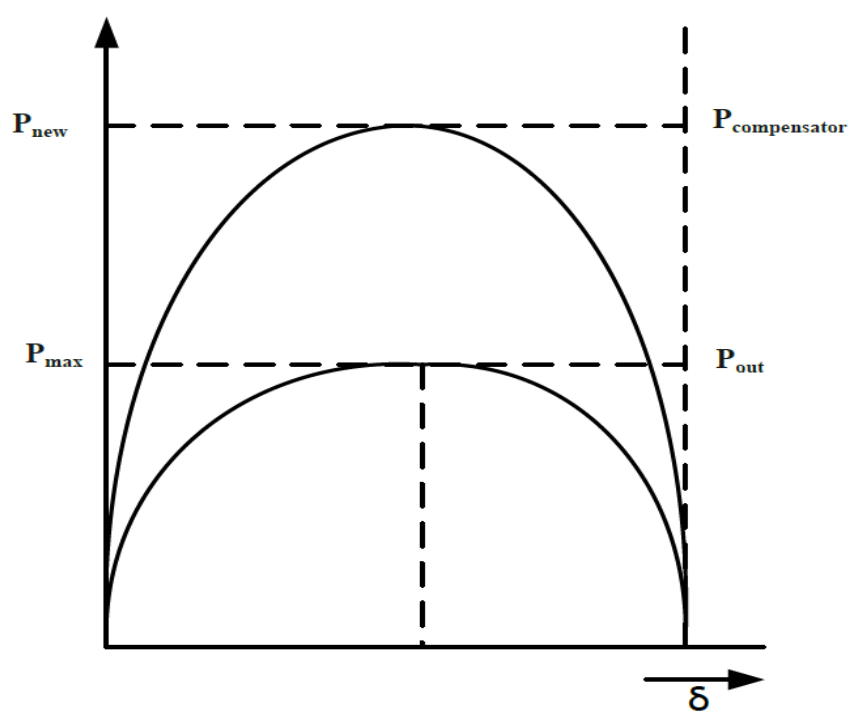

Fig.6(b) P- $\delta$ curve of mode 1.

$$
\begin{gathered}
P_{\text {old }}=\frac{V_{S} \times V_{R}}{X} \times \sin (\delta 1) \\
P_{\text {New }}=\frac{V_{\text {Seff }} \times V_{R}}{X} \times \sin (\delta)
\end{gathered}
$$

\section{B. Impedance Regulator}

JREAS, Vol. 05, Issue 03, July 2020 
In this mode the impedance of line is modulate via modulating the injected voltage of line by SSSC. Whenever the voltage is injected in quadrature, the impedance will compensate with current at 90 degrees. This mode is explained by the voltage phasor diagram as shown in fig.7(a). In this mode, the phasor diagram clearly shows that voltage $\mathrm{Vpq}$ is perpendicular to the line current. It is a virtual kind of voltage compensation because though voltage $\mathrm{Vpq} \perp$ Iline but IX will remains same as $\mathrm{KIX}+\mathrm{IX}-\mathrm{KIX}=\mathrm{IX}$. Effective voltage will always $\pm \mathrm{VS}$ which will never equal because line compensation is zero. Power angle curve is shown in fig.7(b).

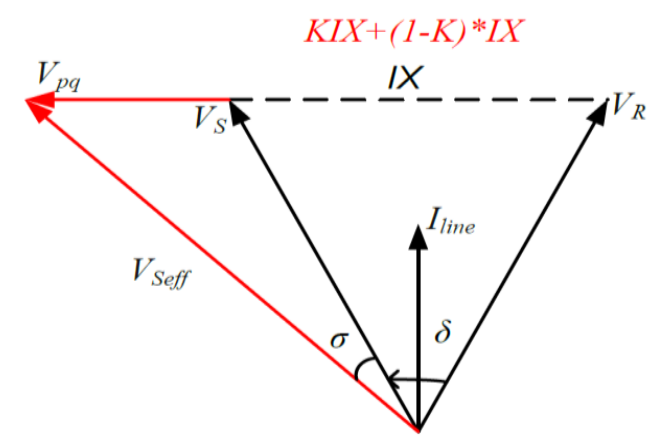

Fig.7(a). Impedance regulator mode.

$$
\begin{gathered}
P_{\text {Old }}=\frac{V_{S} \times V_{R}}{X} \times \sin (\delta) \\
P_{\text {New }}=\frac{V_{S} \times V_{R}}{(1-K) X} \times \sin (\delta) \\
P_{\text {New }}=\frac{V_{\text {Seff }} \times V_{R}}{X} \times \sin (\delta)
\end{gathered}
$$

Where $\mathrm{K}=$ Degree of compensation.

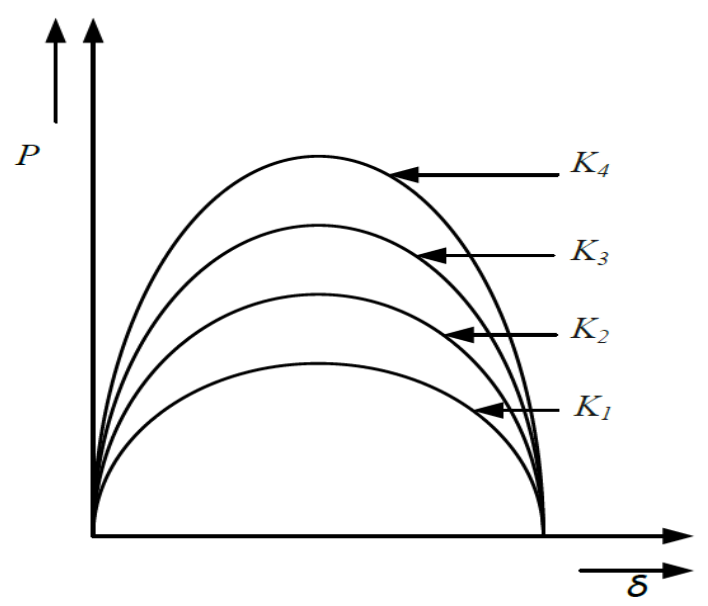

Fig.7(b). P- $\delta$ curve of mode 2.

Power angle curve of impedance regulator mode depends on degree of compensation viz., $\mathrm{K}$.

\section{Quadrature Booster}

Quadrature booster mode is explained by the voltage phasor diagram as shown in fig.8(a). In this mode, the phasor diagram clearly shows that voltage $\mathrm{Vpq}$ is injected at 90 degrees with sending end voltage VS . Therefore, angle of phasor diagram will increases from $\delta$ to $\sigma$. $\sigma$ is the angle made in between sending end voltage VS and VSeff. This mode is operated by angle $\delta+\sigma$. In this mode voltage stability increases by limiting angle $\delta+\sigma$ and power will not increase. VSeff will depends on how much Vpq will be injected and Vpq will depends on angle $\sigma$. In this mode angle between Vf and VS will remain fixed at perpendicular that's why it is called as quadrature booster mode.

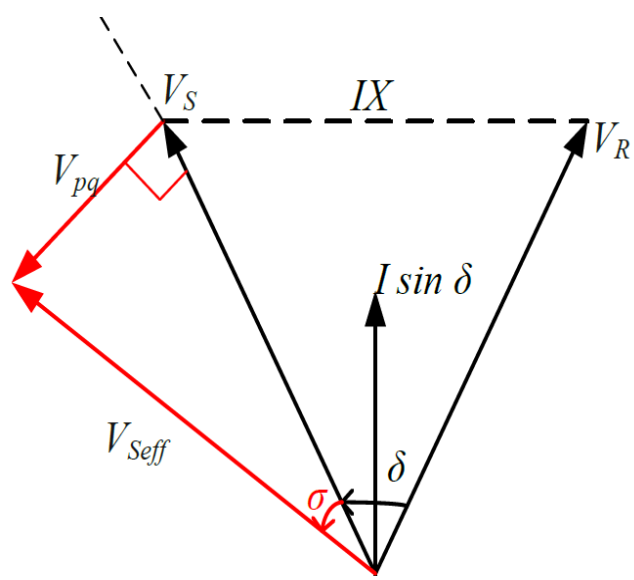

Fig.8(a). Phasor diagram of mode 3.

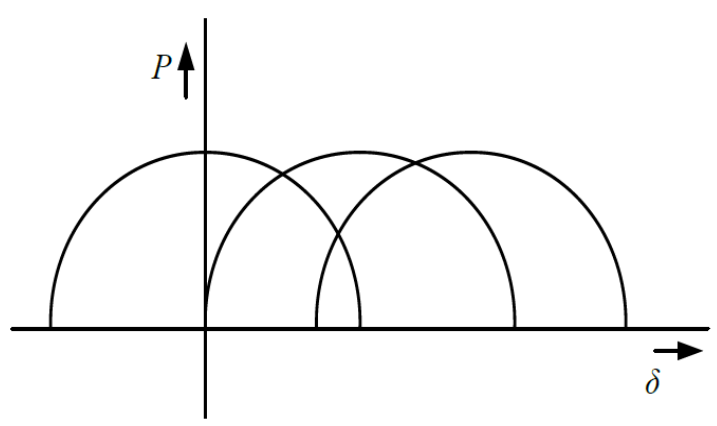

Fig. $8(b)$. P- $\delta$ curve of mode 3.

As shown in fig.8(b), operating region increases of power angle curve.

$$
\begin{aligned}
P_{\text {Old }} & =\frac{V_{S} \times V_{R}}{X} \times \sin (\delta) \\
P_{\text {New }} & =\frac{V_{\text {Seff }} \times V_{R}}{X} \times \sin (\delta \pm \sigma) \\
\sin \sigma & =\frac{V_{P q}}{V_{S e f f}} \\
\tan \sigma & =\frac{V_{P q}}{V_{S}} \\
V_{P q} & =V_{S} \times \tan \sigma
\end{aligned}
$$

\section{Pure Phase Shifter}

Pure phase shifter mode is explained by the voltage phasor diagram as shown in fig.9. Here in this mode only angle should change but voltage should not change. Sending end voltage VS is equal to VSeff and power increases. 


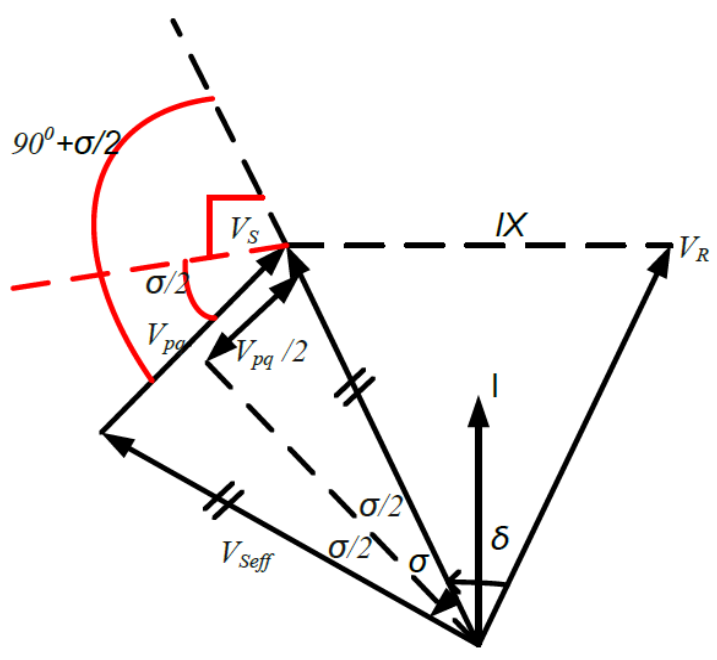

Fig.9. Phasor diagram of mode 4.

$\delta$ is the angle in between sending end and receiving end voltage. Isosceles triangle is forming in phasor diagram with angle $\sigma$ between sending end and controller voltage.

Therefore, by applying basic trigonometry we get,

$\sin \frac{\sigma}{2}=\frac{V_{P q} / 2}{V_{S}}$

$V_{P q}=2 V_{S} \sin \left(\frac{\sigma}{2}\right)$

Angle made in between $V_{S}$ and $\mathrm{V}_{\mathrm{pq}}$ is $90_{0}+\sigma / 2$.

\section{System Parameters}

All the quantities are taken in their standard SI units, and simulated using same standard quantities.

Table 1. System parameters used in simulation

\begin{tabular}{|c|c|}
\hline System Parameters & Values \\
\hline Sending End Voltage(VS) & $100 \mathrm{KV}$ \\
\hline Frequency(Hertz) & $50 \mathrm{hz}$ \\
\hline Sending End Phase Angle & 150 \\
\hline $\begin{array}{c}\text { Receiving End } \\
\text { Voltage(VR) }\end{array}$ & $100 \mathrm{KV}$ \\
\hline $\begin{array}{c}\text { Receiving End Phase } \\
\text { Angle }\end{array}$ & $0^{\circ}$ \\
\hline Inductor(L) & 0.4456 Henry \\
\hline Resistor(R) & 140 ohms \\
\hline
\end{tabular}

\section{Simulations and results}

The simulation has been performed for all four operational modes using MATLAB/SIMULINK. The parameters are set according to Table 1. With minor changes, we can implement model to carry out all four modes of SSSC. SIMULATION environment and then voltages in across have been shown in Fig.10. The results have been given in waveform (from 10 to 13 ).

\section{Pure Voltage Regulator}

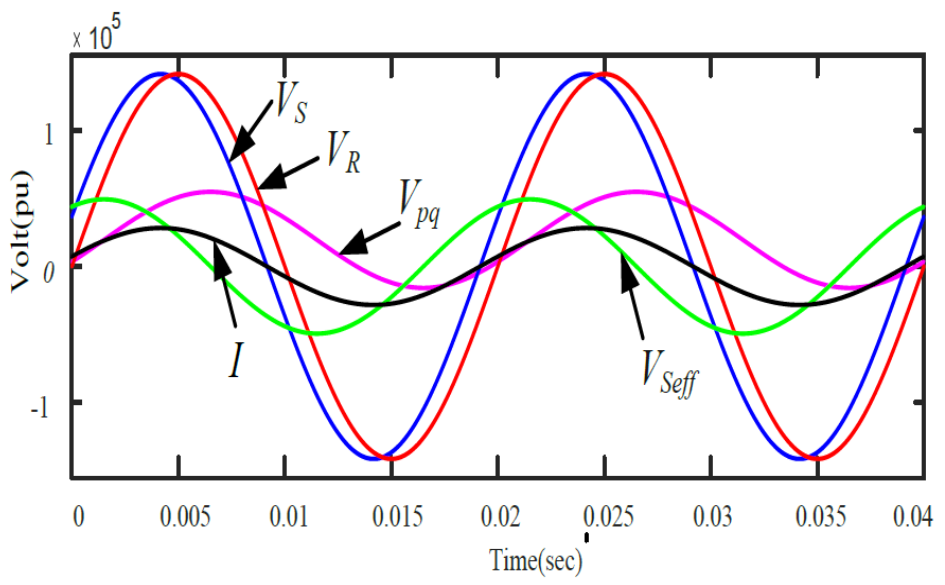

Fig. 10. Simulation output of mode 1.

As shown in fig.5., voltage $V_{p q}$ is exactly in phase with Vs. The resultant is. $V_{\text {seff }}=V_{s}+V_{\text {pq }}$.

\section{Impedance Regulator}

As shown in fig.6. $\mathrm{V}_{\mathrm{pq}}$ is perpendicular to line current. The impedance will compensate with current at 90 degrees. Fig.6., shows that $V_{p q}$ injected in exact phase of its Vs. Detail analysis we discussed in SSSC modes.

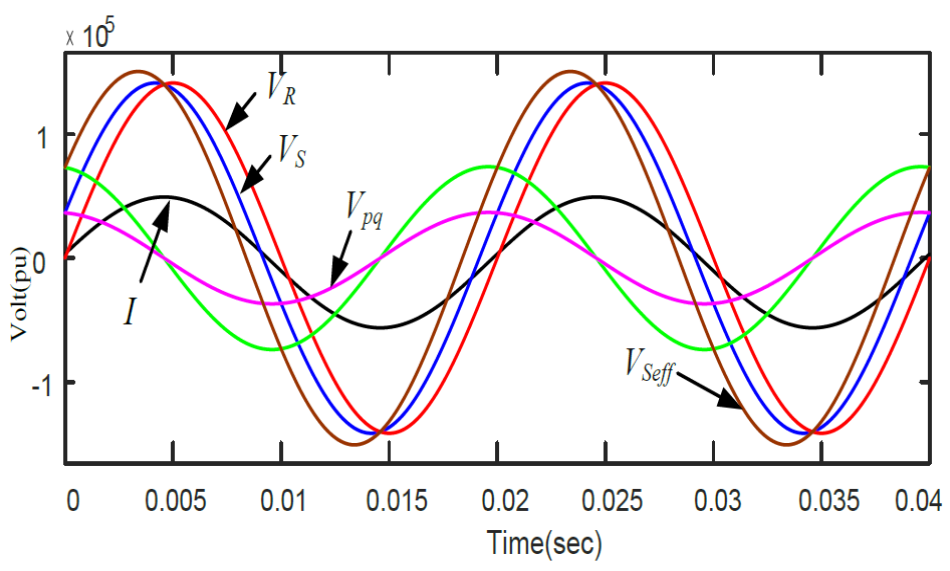

Fig. 11. Simulation output of mode 2.

3. Quadrature Booster

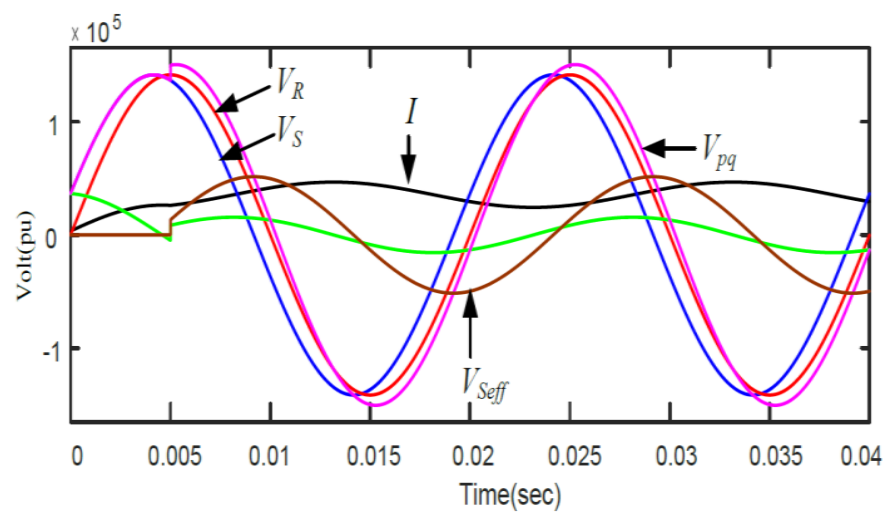

Fig. 12. Simulation output of mode 3. 
As shown in fig.7., voltage $V_{\text {pq }}$ is injected at 90 degrees with sending end voltage $V_{S}$.

\section{Pure Phase Shifter}

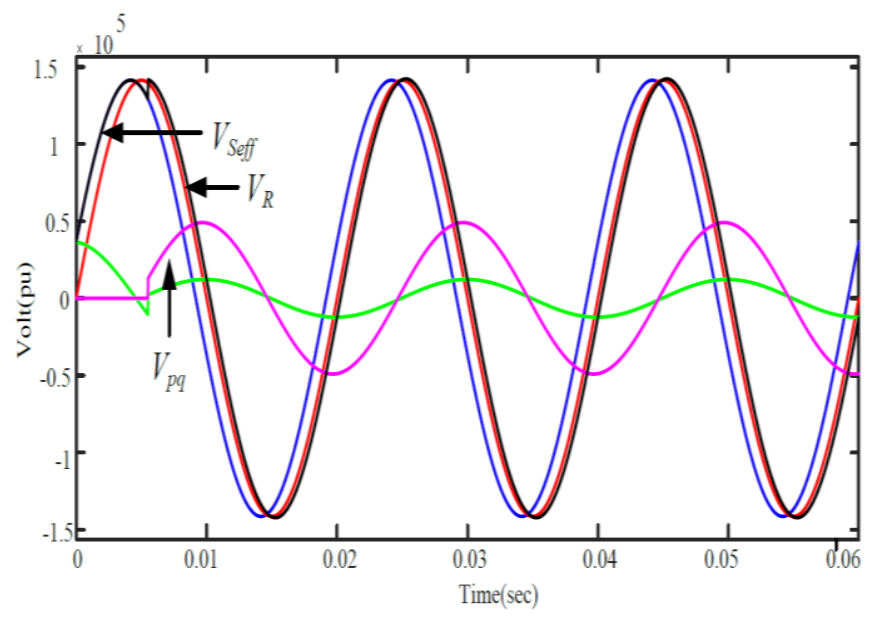

Fig. 13. Simulation output of mode 4 .

As shown in fig.8., Sending end voltage Vs is equal to Vseff and power increases. In this mode only angle should change but voltage should not change.

\section{Conclusion}

In this paper, simulations of four modes of SSSC are located in MATLAB. the primary role of SSSC is controlling the active and reactive powers; besides these it could fairly enhance the transient oscillations of the device. SSSC is able to controlling the electricity at a favored factor on the transmission line. It injects a fast changing voltage in collection with the road no matter the significance and section of the modern. The capability of SSSC to alternate each reactive and active strength makes it feasible to compensate each the reactive and resistive line voltage drops and their via keep a excessive effective $\mathrm{X} / \mathrm{R}$ ratio for the line independently of the diploma of collection reimbursement. as a consequence choicest power transmission may be attained even at a high degree of series compensation. With using fast controls, minimizing the effect of device disturbances, thereby lowering conventional stability margin necessities. The noncapacitor like conduct, the advanced operating characteristics and application flexibility that SSSC offers efficiently is a repayment for power waft manage and device balance development.

\section{References}

[1] Shea, J. J. "Understanding FACTS-concepts and technology of flexible AC transmission systems [Book Review]." IEEE Electrical Insulation Magazine 18.1 (2002): 46-46.

[2] Mathur, R. Mohan, and Rajiv K. Varma. Thyristor-based FACTS controllers for electrical transmission systems. John Wiley \& Sons, 2002.

[3] Gyugyi, Laszlo, Colin D. Schauder, and Kalyan K. Sen. "Static synchronous series compensator: a solid-state approach to the series compensation of transmission lines." IEEE Transactions on power delivery 12.1 (1997): 406-417.

[4] El-Moursi, M. S., and A. M. Sharaf. "Novel controllers for the 48pulse VSCSTATCOM and SSSC for voltage regulation and reactive power compensation." IEEE Transactions on Power systems 20, no. 4 (2005): 1985-1997.

[5] Sode-Yome, Arthit, Nadarajah Mithulananthan, and Kwang Y. Lee. "Static voltage stability margin enhancement using STATCOM, TCSC and SSSC." 2005 IEEE/PES Transmission \& Distribution Conference \& Exposition: Asia and Pacific. IEEE, 2005.

[6] Kamarposhti, Mehrdad Ahmadi, and Hamid Lesani. "Effects of STATCOM, TCSC, SSSC and UPFC on static voltage stability." Electrical Engineering 93, no. 1 (2011): 33-42.

[7] Rai, Dipendra, Sherif O. Faried, G. Ramakrishna, and Abdel-Aty Edris. "An SSSC-based hybrid series compensation scheme capable of damping subsynchronous resonance." IEEE transactions on power delivery 27 , no. 2 (2011): 531-540

[8] Taheri, Hamed, et al. "Application of Synchronous Static Series Compensator (SSSC) on enhancement of voltage stability and power oscillation damping." IEEE EUROCON 2009. IEEE, 2009.

[9] Sen, Kalyan K. "SSSC-static synchronous series compensator: theory, modeling, and application." IEEE Transactions on power delivery 13 , no. 1 (1998): 241-246.

[10] Norouzi, Amir H., and A. M. Sharaf. "Two control schemes to enhance the dynamic performance of the STATCOM and SSSC." IEEE Transactions on Power delivery 20, no. 1 (2005): 435-442. 